\title{
Nova história da Fundação Rockefeller: a odisseia da saúde global revisitada
}

\author{
New history of the Rockefeller Foundation: \\ the odyssey of global health revisited
}

\author{
Rodrigo Cesar da Silva Magalhães \\ Professor, Departamento de História/Colégio Pedro II. \\ rodrigocesa@hotmail.com
}

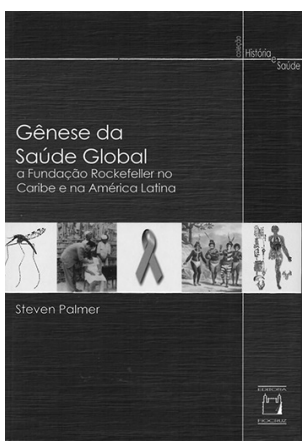

PALMER, Steven. Gênese da saúde global: a Fundação Rockefeller no Caribe e na América Latina. Rio de Janeiro: Editora Fiocruz. 2015. 420p.

\begin{abstract}
A atuação da Fundação Rockefeller no campo da saúde pública nas Américas, na primeira metade do século XX, é um objeto de pesquisa cada vez mais valorizado. Contudo, as campanhas inaugurais da organização, desenvolvidas em seis países da América Central e do Caribe, ainda não haviam merecido a atenção dos historiadores. Essa lacuna foi preenchida por Steven Palmer - professor de história da saúde internacional da Universidade de Windsor, no Canadá no livro Gênese da saúde global: a Fundação Rockefeller no Caribe e na América Latina.
\end{abstract}

A obra é uma versão revista e ampliada da edição original em inglês, publicada em 2010 pela Universidade de Michigan com o título Launching global health: the Caribbean odyssey of the Rockefeller Foundation. A edição brasileira traz um capítulo inédito (capítulo 7: "Experimento e responsabilidade na saúde internacional"), no qual Palmer analisa as consequências de centenas de mortes causadas por superdosagens de óleo de quenopódio - um novo vermífugo utilizado pela Comissão de Saúde Internacional em 1915 no lugar do tratamento-padrão com timol durante as campanhas de combate à ancilostomíase da Fundação Rockefeller no Brasil e na Colômbia e sua relação com a emergência de uma ética em saúde internacional.

O livro de Palmer é o primeiro a analisar em conjunto, como um único projeto sanitário, os seis programas-piloto destinados ao combate à ancilostomíase que a Comissão de Saúde Internacional (CSI) da Fundação Rockefeller implementou, a partir de 1914, em Guiana Britânica, Trinidad-Tobago, Costa Rica, Guatemala, Nicarágua e Panamá. ${ }^{1} \mathrm{O}$ autor defende que tais programas serviram "como um laboratório para descobrir e testar elementos de um sistema de saúde global para o século XX" (p.20) e marcaram a "gênese da saúde global", cujas origens seriam periféricas. ${ }^{2}$

Com seu trabalho, Palmer insere-se entre os autores que, a partir dos anos 1980, analisaram as atividades filantrópicas da Fundação Rockefeller procurando destacar a complexidade dos 
encontros entre uma instituição em permanente mudança e uma gama de realidades políticas e culturais (Bullock, 1980; Ettling, 1981). Tais estudos foram pioneiros na preocupação em ressaltar o papel dos atores e instituições sanitárias locais. Contudo, fomentaram um consenso sobre o modelo de saúde internacional desenvolvido pela Fundação Rockefeller, segundo o qual a agenda sanitária da organização era imposta de cima para baixo aos países anfitriões (Birn, 2006), que acolhiam uma visão estritamente biomédica da saúde pública (Farley, 2004), embasada por uma variante norte-americana de medicina tropical que procurava atribuir patologias tropicais às diferentes raças (Anderson, 2006).

Em claro desafio a esse consenso, Palmer argumenta que tanto os atores quantos os programas médicos locais foram fundamentais para a construção da saúde pública na América Central e no Caribe. Nesse sentido, seu livro nos oferece uma análise mais matizada e complexa da saúde pública internacional. Segundo o autor, o formato e o desfecho que tiveram os programas implementados pela Fundação Rockefeller nos seis países analisados resultaram em grande medida das dinâmicas históricas locais, e não da aplicação de cima para baixo de um conjunto bem definido de políticas e práticas de saúde. Tais programas dependeram de uma intensa negociação entre os trabalhadores de campo da organização e as populações nativas, bem como entre os dirigentes norte-americanos e os médicos e políticos locais. Desse modo, eles não podem ser considerados nem ocidentais nem locais em sua totalidade, uma vez que resultaram de adaptações tanto das prerrogativas institucionais da Fundação Rockefeller quanto das práticas de combate às doenças adotadas nos países anfitriões.

Palmer demonstra habilmente como os especialistas da Fundação Rockefeller tiveram que se adaptar às condições e às convenções sociais, culturais e políticas locais. Alguns deles chegaram, inclusive, a aceitar nomeações para cargos na estrutura estatal do sistema de saúde como forma de melhor atingir os objetivos da organização. Esse teria sido, então, o "modelo" de saúde internacional desenvolvido pela Fundação Rockefeller, testado e aperfeiçoado nas incursões da organização na América Central e no Caribe na década de 1910, e que se caracterizava também pela possibilidade de incorporação aos programas sanitários de praticamente qualquer demanda das comunidades médicas e dos governos locais no campo da saúde pública.

Na Guiana Britânica e em Trinidad, por exemplo, diretores norte-americanos como Benjamim Washburn, George Payne e Frederick Dershimer empreenderam esforços conscientes para "crioulizar" a narrativa biomédica da ancilostomíase e seu tratamento, como forma de lidar com a complexidade étnica dos funcionários e da população-alvo. A experiência mais fascinante de tradução etnomédica foi o panfleto "O demônio que se transformou em vermes", que Palmer analisa no capítulo 5. Elaborado por Dershimer e apresentado como uma extensão - "a vigésima sexta história" - de uma popular coleção de histórias na língua hindi chamada "Vinte e cinco histórias de um demônio", o panfleto revela uma preocupação dos diretores do programa em transmitir a mensagem da higiene mediante a adaptação de narrativas tradicionais e bem conhecidas pelas populações locais. Palmer destaca que esforços de tradução médica como esse contribuíram para legitimar e promover o pluralismo médico.

A importância conferida por Palmer aos atores e programas médicos locais e sua preocupação em romper com a ideia de que a filantropia da Fundação Rockefeller no campo da saúde foi dirigida de cima para baixo pela organização transparecem na seleção das fontes 
que embasaram seu estudo. Um dos grandes diferenciais do seu trabalho é a minuciosa pesquisa realizada em arquivos nacionais da Costa Rica, de Trinidad-Tobago e da Guatemala e a análise de uma gama de periódicos locais e regionais, revistas médicas e científicas e manuscritos em língua espanhola produzidos pelas comunidades médicas locais. A escolha de fontes dessa natureza nos permite vislumbrar as reações das populações dos países anfitriões à presença da Fundação Rockefeller, os significados culturais e políticos que elas atribuíram às iniciativas sanitárias da organização e às doenças que as flagelavam, bem como a maneira pela qual os médicos locais moldaram, de forma ativa e consciente, os primeiros programas desenvolvidos pela Comissão de Saúde Internacional (CSI) fora dos EUA.

Na conclusão do livro, Palmer evita avaliar os programas-piloto da Fundação Rockefeller na América Central e no Caribe em termos de sucesso ou fracasso. Ao contrário, sua preocupação reside em mapear o que funcionou e o que não deu certo em cada um deles, bem como as adaptações que surgiram ao longo de sua implementação em realidades distintas e em meio a uma grande variedade de práticas e métodos de tratamento. Ele conclui que "os resultados da intervenção relacionada à ancilostomíase no 'laboratório' latino-americano e caribenho ... devem ser vistos como o desenvolvimento de um repertório de conhecimentos e métodos institucionais internacionais" (p.295).

A perspectiva de análise adotada está em sintonia com o argumento principal do autor, segundo o qual as campanhas sanitárias e de combate à ancilostomíase que se desenvolveram nos programas-piloto foram resultado de um intenso processo de negociação. A capacidade de adaptação às condições locais foi justamente o fator que possibilitou à filantropia da Fundação Rockefeller alcançar o posto de ator mais importante na construção da saúde global na primeira metade do século XX. O livro de Palmer é uma contribuição valiosa para compreendermos as raízes centro-americanas e caribenhas - periféricas, portanto - dessa odisseia, e interessa tanto aos historiadores da medicina e da saúde pública quanto aos da ciência, do império e das organizações internacionais.

\section{NOTAS}

${ }^{1}$ A Comissão de Saúde Internacional (International Health Comission) da Fundação Rockefeller foi criada em 1913, tendo seu nome alterado para Junta de Saúde Internacional (International Health Board) em 1916. Essa designação vigorou até 1927, quando a agência passou a chamar-se Divisão de Saúde Internacional (International Health Division). No livro, como forma de evitar confusão e a constante mudança de acrônimos (CSI/JSI/DSI), Palmer optou por designar a agência como Saúde Internacional, assumindo a ideia de que, na época de seu estudo, "a instituição e o sistema genérico eram amplamente limítrofes" (p.307-308, nota 2). No presente artigo, utilizei a denominação Comissão de Saúde Internacional (CSI), que vigorava quando a agência deu início aos programas de combate à ancilostomíase na América Central e no Caribe em 1915.

2 Palmer (2004) já havia anunciado essa tese em um estudo sobre a campanha contra a ancilostomíase da Fundação Rockefeller na Costa Rica, no qual explicitou o conceito de "precedência periférica" e analisou em que medida os indivíduos, grupos intelectuais e instituições do país foram capazes de transformar os esforços da organização em um veículo para a consolidação de um projeto de saúde pública já existente, elaborado localmente, oferecendo uma comparação inicial com a experiência dos demais países centro-americanos. 


\section{REFERÊNCIAS}

ANDERSON, Warwick.

Colonial pathologies: American tropical medicine, race, and hygiene in the Philippines. Durham:

Duke University Press. 2006.

BIRN, Anne-Emanuelle.

Marriage of convenience: Rockefeller international health and revolutionary Mexico. Rochester: University of Rochester Press. 2006.

BULLOCK, Mary Brown. An American transplant: the Rockefeller Foundation and Peking Union Medical College. Berkeley: University of California Press. 1980.

ETTLING, John.

The germ of laziness: Rockefeller Philanthropy and public health in the New South. Cambridge: Harvard University Press. 1981.
FARLEY, John.

To cast out disease: a history of the international health division of the Rockefeller Foundation (1913-1951). New York: Oxford University Press. 2004.

PALMER, Steven.

Launching global health: the Caribbean odyssey of the Rockefeller Foundation. Ann Arbor: The University of Michigan Press. 2010.

PALMER, Steven.

Saúde imperial e educação popular: a Fundação Rockefeller na Costa Rica em uma perspectiva centro-americana, 1914-1921. In: Hochman, Gilberto; Armus, Diego (Org.). Cuidar, controlar, curar: ensaios históricos sobre saúde e doença na América Latina e Caribe. Rio de Janeiro: Editora Fiocruz. p.217-248. 2004. 